\title{
Efficacy and safety of neostigmine for neuromuscular blockade reversal in patients under general anesthesia: a systematic review and meta-analysis
}

\author{
Wentao Ji", Xiaoting Zhang", Jia Liu", Guolin Sun, Xiandong Wang, Lulong Bo, Xiaoming Deng \\ Faculty of Anesthesiology, Changhai Hospital, Shanghai, China \\ Contributions: (I) Conception and design: L Bo, X Deng; (II) Administrative support: X Deng; (III) Provision of study materials or patients: W Ji, X \\ Zhang; (IV) Collection and assembly of data: W Ji, J Liu; (V) Data analysis and interpretation: X Zhang, G Sun, X Wang; (VI) Manuscript writing: \\ All authors; (VII) Final approval of manuscript: All authors. \\ \#These authors contributed equally to this work. \\ Correspondence to: Dr. Lulong Bo; Dr. Xiaoming Deng. Faculty of Anesthesiology, Changhai Hospital, Shanghai, China. \\ Email: bartbo@smmu.edu.cn; deng_x@yahoo.com.
}

\begin{abstract}
Background: Since the antagonistic effect of neostigmine on muscle relaxation is still controversial, this study aimed to evaluate the efficacy and safety of neostigmine for the reversal of neuromuscular blockade in patients recovering from general anesthesia.

Methods: Multiple databases, including PubMed, Web of Science, the Cochrane Library, and Chinese National Knowledge Infrastructure (CNKI), were electronically searched up to August 2021. Relevant studies on the use of neostigmine for neuromuscular blockade reversal in patients under general anesthesia were retrieved. Two reviewers independently screened and extracted data from the retrieved studies, and assessed their risk of bias. Review Manager 5.2 was used to evaluate the efficacy and safety of neostigmine based on the included articles. Heterogeneity and related subgroup, sensitivity, and bias analyses were carried out.

Results: The analysis included 14 studies involving 2,109 patients, including 1,209 in the neostigmine group and 990 in the control group. Results from the random-effects model showed that neostigmine reduced the length of stay in the post-anesthesia care unit [mean difference $(\mathrm{MD})=-17.73 ; 95 \%$ confidential interval (CI): -22.06 to $-13.41 ; \mathrm{P}<0.0001]$, the time to recovery of train-of-four ratio $\geq 0.9(\mathrm{MD}=-16.60$; 95\% CI: -23.67 to $-9.52 ; \mathrm{P}<0.0001$ ), and the extubation time ( $\mathrm{MD}=-16.69 ; 95 \% \mathrm{CI}:-28.22$ to -5.17 ; $\mathrm{P}=0.005$ ). However, no difference was observed in adverse events between the neostigmine and control groups [odds ratio $(\mathrm{OR})=0.97 ; 95 \% \mathrm{CI}$ : 0.84-1.12; $\mathrm{P}=0.71$ ]. Subgroup analyses adjusted for the dosage of neostigmine had no effect on the above results.
\end{abstract}

Conclusions: Neostigmine can effectively and safely enhance neuromuscular recovery from nondepolarizing muscle relaxants in patients under general anesthesia.

Keywords: Neostigmine; neuromuscular blockade; anesthesia

Submitted Sep 29, 2021. Accepted for publication Nov 09, 2021.

doi: $10.21037 / \mathrm{atm}-21-5667$

View this article at: https://dx.doi.org/10.21037/atm-21-5667

\section{Introduction}

The proportion of the global population that receives surgical procedures under anesthesia is increasing annually. The development of short-acting anesthetics has provided opportunities for enhanced recovery after surgery (1).
Most anesthesia procedures involve the intraoperative use of muscle relaxants to ensure optimal surgical conditions, facilitate tracheal intubation while decreasing the potential for vocal cord trauma, and allow full control of the patient's respiratory function. These compounds also reduce the 
occurrence of intraoperative adverse events (2). However, surgical patients often face high risks of developing postoperative complications, including pain, nausea and vomiting, and impaired pulmonary function.

Pulmonary function impairment resulting from inadequate neuromuscular recovery following general anesthesia can contribute to critical respiratory events in the post-anesthesia care unit (PACU). Postoperative residual neuromuscular blockade, which is associated with adverse patient outcomes, persists with an unacceptably high incidence (3). The neuromuscular block should be routinely monitored in order to guide the administration of muscle relaxant doses and determine the adequacy of reversal. Ali et al. (4) introduced train-of-four (TOF) nerve stimulation in the early 1970s. Four super-maximum stimuli were emitted every 0.5 seconds $(2 \mathrm{~Hz})$, and the muscle response to the fourth stimulus was compared with that to the first stimulus. The attenuation of muscle contractility caused by repetitive nerve stimulation provides a basis for evaluating neuromuscular block reversal (5). Devices providing digital readings of the TOF ratio (TOFR) should be considered. Viby-Mogensen et al. (6) defined a TOFR of 0.7 as a $42 \%$ residual block incidence after using longacting neuromuscular blocking drugs.

Among patients who received muscle relaxants during surgery, residual neuromuscular block (defined as TOF ratio $<0.9)$ commonly occurs during endotracheal extubation or the PACU stay, with an incidence of $88 \%$ and $83 \%$, respectively (7). Reports suggests that residual neuromuscular block is associated with clinical complications, including hypoxemia, shortness of breath, upper respiratory tract disease, dysphagia, hypercapnia, slurred speech, blurred vision, and general discomfort (8-12).

Neostigmine is a quaternary ammonium compound with a strong alkaline carbamoyl group. Neostigmine binds to the anion site of acetylcholinesterase and is then transferred to the esterification site and hydrolyzed. It is mainly used to reverse muscle relaxants, at an intravenous dose of 0.05 to $0.07 \mathrm{mg} / \mathrm{kg}$. Its onset of action is generally evident within $1 \mathrm{~min}$, with the peak effect occurring within $10 \mathrm{~min}$. Neostigmine has a duration of action of 20 to $30 \mathrm{~min}$, and an elimination half-life of approximately $77 \mathrm{~min}$ (13).

Kopman et al. (14) suggested that the TOFR should above 0.9 and close to 1 , and found that the weakness of neck and jaw muscles was significantly underestimated when the TOFR reached 1 . Their observations remind us to not only to rely on the TOFR but to also evaluate the individual patient, as the effects of muscle relaxants can vary widely. Patients with TOF ratio less than 0.90 had an increased risk of hypoxic events, impaired respiratory control during hypoxia, airway obstruction, aspiration, postoperative pulmonary complications and myasthenia (2). Neostigmine can shorten time to recovery of TOFR $\geq 0.9$ may help to decrease the incidence of postoperative complications.

Neostigmine has imperative research significance for the reversal of neuromuscular blockade after anesthesia. However, there is still doubt about the effects of neostigmine for reversal of neuromuscular blockade (7). To evaluate the efficacy and safety of neostigmine for neuromuscular blockade reversal during recovery from general anesthesia, this meta-analysis compared the typical postoperative recovery indicators including length of PACU stay, time to recovery of TOFR $\geq 0.9$, extubation time, and adverse events between the neostigmine and control groups. In this research, we included 5 new trials published after 2016 and update the meta-analysis about the efficacy and safety of neostigmine for neuromuscular blockade reversal in patients under general anesthesia. In addition, we divided three clinical effects based on the patients' age and further analyzed safety according to the adverse events details.

We present the following article in accordance with the PRISMA reporting checklist (available at https://dx.doi. org/10.21037/atm-21-5667).

\section{Methods}

\section{Literature search strategy}

Two investigators (JWT and ZXT) independently searched the PubMed, Web of Science, Cochrane Library, and CNKI (Chinese National Knowledge Infrastructure) databases for relevant studies. The search terms and related variants used included "neostigmine", "neuromuscular blockade" or "nerve block", and "general anesthesia". The reference lists and citations of retrieved studies were manually searched to identify additional studies of interest. A comprehensive search was performed to identify all relevant studies regardless of language or publication status (published, unpublished, in the press, and ongoing) up to August 2021.

\section{Study selection}

Two investigators (JWT and ZXT) independently reviewed all potentially relevant manuscripts. Cases of disagreement 
or uncertainty were resolved by a third investigator (BLL). The initial stage of study included reviewing article titles and abstracts. The following articles were excluded at this stage: (I) studies not written in English or Chinese; (II) non-original research studies; (III) conference abstracts or presentations; and (IV) duplicate studies.

The second stage of study included full-text reviews, and the selection of articles against the inclusion and exclusion criteria. The studies included in this systematic review and meta-analysis met the following inclusion criteria: (I) published in peer-reviewed journals; and (II) reported outcome measures relating to neostigmine. The exclusion criteria comprised the following: (I) studies with non-RCT methodology; (II) studies involving patients not under general anesthesia; and (III) studies without fully available or any relevant clinical outcome measures. Reviews, qualitative studies, animal trials, and laboratory studies were also excluded.

\section{Data extraction}

Two investigators (JWT and ZXT) independently extracted the data and evaluated the quality of all eligible studies. The quality of the included studies and validity of the extracted data were then verified independently. Differences between the investigators were resolved through discussion or by a third investigator (BLL) if necessary. The extracted data were as follows: first author, year of publication, location, income level, study population, study design, and study participant characteristics (sample size, age, and sex).

\section{Assessment of methodological quality}

The RevMan 5.3 software (The Nordic Cochrane Centre, The Cochrane Collaboration, Copenhagen, Demark) was employed for the assessment of selection bias, performance bias, attrition bias, and reporting bias, and to generate risk of bias tables. The risk of bias and quality of each included article were independently assessed by two reviewers using Cochrane risk assessment tool (JWT and ZXT), who assessed each risk of bias item as "low", "high", or "unclear". Any discrepancies between the two reviewers were resolved by a consulting group comprising two experts in anesthesia specialty (BLL and DXM). Publication bias was determined based on visual symmetry of funnel plots, with asymmetry suggesting possible publication bias.

\section{Statistical analysis}

Data were pooled, and mean difference [MD, with $95 \%$ confidence interval (CI)] was used for continuous outcomes including the length of PACU stay, time to recovery of TOFR $\geq 0.9$, and extubation time. Odds ratios (ORs) were used for dichotomous variables including postoperative nausea and vomiting (PONV), bradycardia, pain, and hypoxemia. Heterogeneity was assessed using the $\mathrm{P}$ value and I-square $\left(\mathrm{I}^{2}\right)$ statistic in the pooled analyses, and these two parameters represent the percentage of total variation across studies. If the $\mathrm{P}$ value was less than 0.1 or the $\mathrm{I}^{2}$ value exceeded $50 \%$, the summary estimate was analyzed by random-effects model; otherwise, a fixed-effects model was applied. Potential publication bias was assessed by Begg's funnel plot and Egger's linear regression test. The existence of publication bias was indicated by a $\mathrm{P}$ value $<0.05$. Additionally, a scenario sensitivity analysis was conducted to evaluate the robustness of the results. All statistical analyses were carried out with Review Manager 5.2 (The Cochrane Collaboration).

\section{Results}

\section{Search process}

Through a search of multiple databases, a total of 855 articles were identified for initial screening. Then, on the basis of their titles and abstracts, 779 of these studies were excluded. The full texts of the remaining 76 studies were carefully examined according to the inclusion and exclusion criteria. Finally, 14 comparative studies were included for metaanalysis. The study selection flow chart is shown in Figure 1.

\section{Characteristics of the included studies}

Table 1 details the main characteristics of the 14 studies included in the meta-analysis (15-28). The mean ages of participants in the studies ranged from 7.3 to 73.3 years old, and the proportion of male participants ranged from $0 \%$ to $63.5 \%$. The follow-up duration lasted from 1 to 3 years. The 14 studies were RCTs or retrospective trials and involved a total of 2,199 patients, of whom 1,209 patients received neostigmine and 990 received control drugs.

\section{Results of quality assessment}

The risk of bias and quality of the included studies were 
Identification of studies via databases and registers

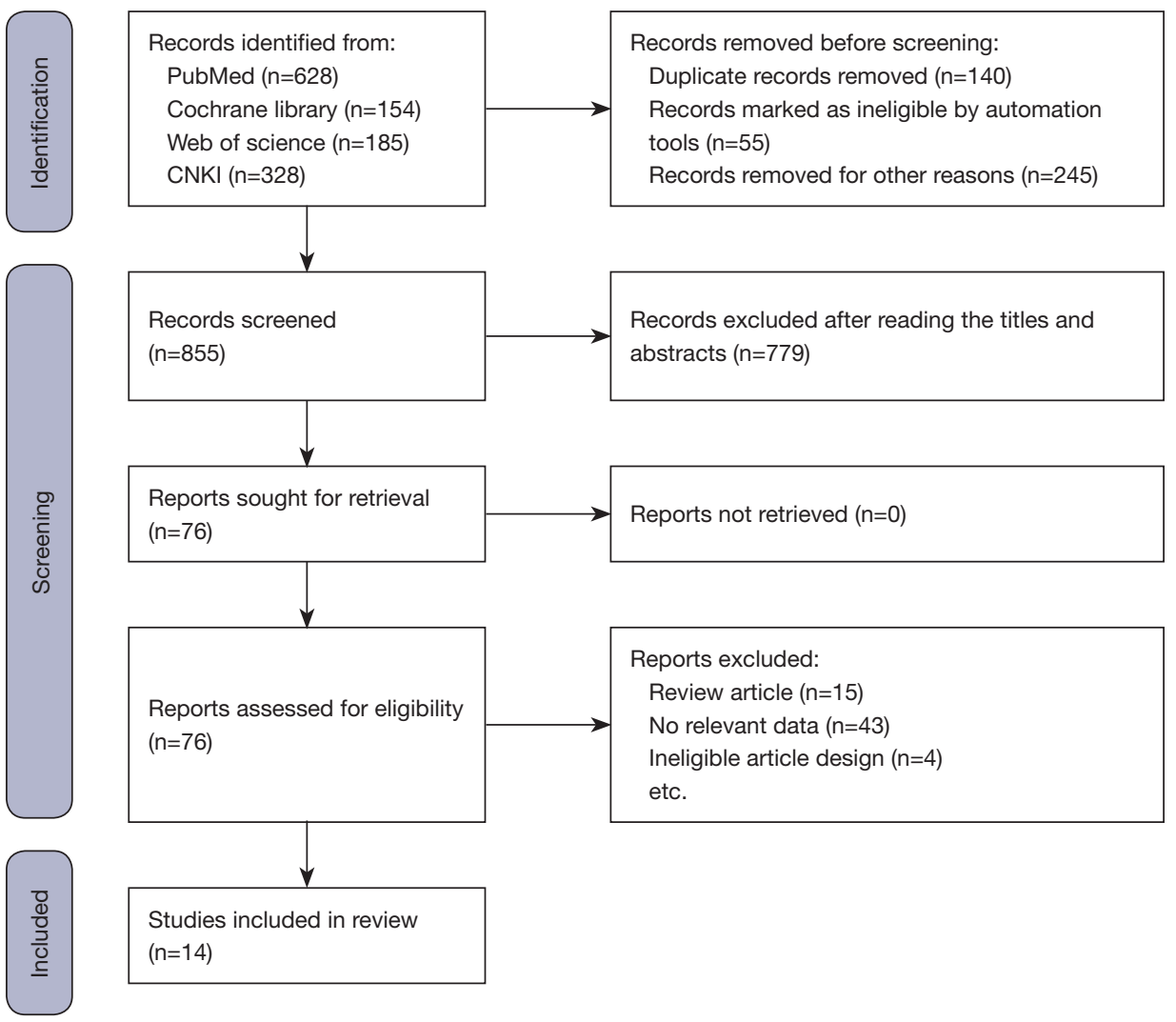

Figure 1 Flow chart of the study selection process for the meta-analysis.

evaluated. The results of quality evaluation showed the studies to have low risk of bias (Figure 2). As shown in Figure 3, only one study had high selection bias (22), one had high attrition bias (15), one had high reporting bias (18), and two had other biases $(17,22)$. Overall, these results evidenced the good quality of the included studies.

\section{Results of meta-analysis}

\section{Length of PACU stay}

Five studies examined the difference in the length of PACU stay between the neostigmine and control groups. Meta-analysis by random-effects model showed that patients in the neostigmine group had a shorter PACU stay than those in the control group ( $\mathrm{MD}=-17.73 ; 95 \%$ CI: -22.06 to $-13.41 ; \mathrm{P}<0.0001 ; \mathrm{I}^{2}=92 \%$; Figure 4). Subgroup analysis based on the dosage of neostigmine indicated that compared to that in the control group, the length of PACU stay was significantly shortened in both the neostigmine $\geq 40 \mu \mathrm{g} / \mathrm{kg}$ (MD $=-18.11 ; 95 \% \mathrm{CI}:-23.16$ to $\left.-13.05 ; \mathrm{P}<0.0001 ; \mathrm{I}^{2}=94 \%\right)$ and neostigmine $<40 \mu \mathrm{g} / \mathrm{kg}$ $\left(\mathrm{MD}=-16.03 ; 95 \% \mathrm{CI}:-26.51\right.$ to $\left.-5.55 ; \mathrm{P}=0.003 ; \mathrm{I}^{2}=83 \%\right)$ groups.

\section{Time to recovery of TOFR $\geq 0.9$}

Seven studies reported the time to recovery of TOFR $\geq 0.9$. Meta-analysis showed that the time to recovery of TOFR $\geq 0.9$ in the neostigmine group was shorter than that in the control group ( $M D=-16.60$; 95\% CI: -23.67 to -9.52 ; $\mathrm{P}<0.0001 ; \mathrm{I}^{2}=100 \%$; Figure 5$)$. In the subgroup analysis, compared to the time to recovery of TOFR $\geq 0.9$ in the control group, the time to recovery of TOFR $\geq 0.9$ was significantly shortened in both the neostigmine $\geq 40 \mu \mathrm{g} / \mathrm{kg}$ ( $M D=-16.19 ; 95 \%$ CI: -24.27 to $\left.-8.11 ; \mathrm{P}<0.001 ; \mathrm{I}^{2}=98 \%\right)$ and neostigmine $<40 \mu \mathrm{g} / \mathrm{kg}$ (MD $=-16.61 ; 95 \% \mathrm{CI}:-26.11$ to $\left.-7.12 ; \mathrm{P}=0.0006 ; \mathrm{I}^{2}=100 \%\right)$ groups. 
Table 1 Characteristics of the included studies

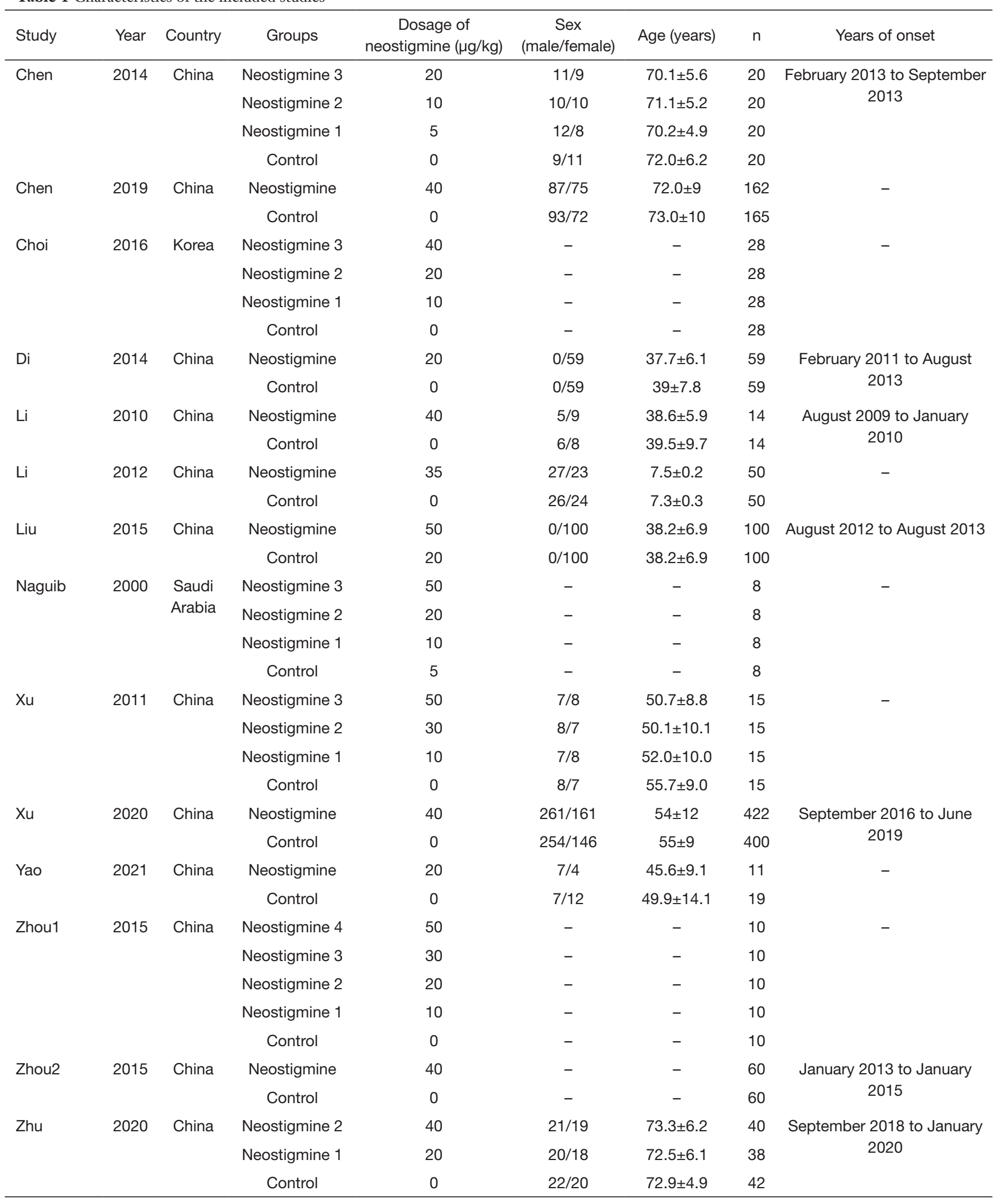




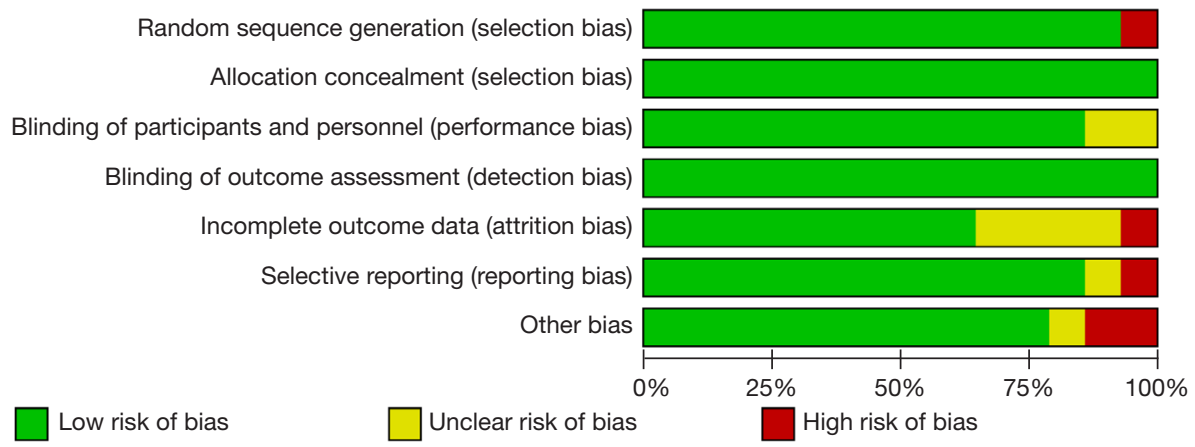

Figure 2 Summary of quality assessment of the included studies. Red, yellow, and green indicate high, unclear, and low risk of bias, respectively.

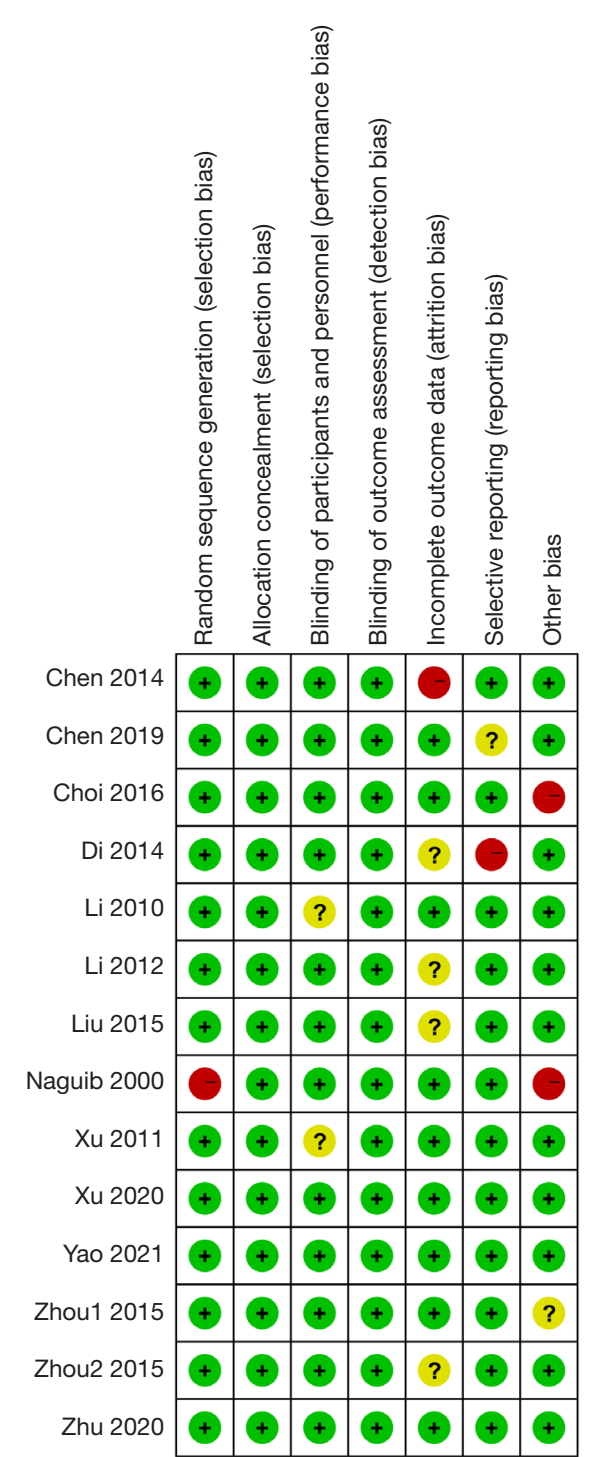

Figure 3 Summary of the risk of bias assessment according to the Cochrane Collaboration's tool. Red, yellow, and green indicate high, unclear, and low risk of bias, respectively.

\section{Extubation time}

Five studies compared the extubation time between the neostigmine and control groups. The extubation time in the neostigmine group was significantly shorter than that in the control group (MD $=-16.69$; 95\% CI: -28.22 to -5.17 ; $\mathrm{P}=0.005 ; \mathrm{I}^{2}=100 \%$; Figure 6). However, in the subgroup analysis, the extubation time showed no differences in the neostigmine $\geq 40 \mu \mathrm{g} / \mathrm{kg}$ (MD $=-22.08 ; 95 \% \mathrm{CI}:-51.97$ to $\left.7.81 ; \mathrm{P}=0.15 ; \mathrm{I}^{2}=99 \%\right)$ and neostigmine $<40 \mu \mathrm{g} / \mathrm{kg}(\mathrm{MD}$ $=-13.84 ; 95 \%$ CI: -28.10 to $\left.-0.42 ; \mathrm{P}=0.06 ; \mathrm{I}^{2}=100 \%\right)$ groups compared with the control group.

\section{Adverse events}

Seven studies reported adverse events in the neostigmine and control groups, and the forest plot is presented in Figure 7. There was no difference in the overall incidence of adverse events between the neostigmine and control groups $\left(\mathrm{OR}=0.97 ; 95 \% \mathrm{CI}: 0.84-1.12 ; \mathrm{P}=0.71 ; \mathrm{I}^{2}=34 \%\right)$. In the subgroup analysis, the incidence of $\mathrm{PONV}$ in the neostigmine group was higher than that in the control group (OR $\left.=1.30 ; 95 \% \mathrm{CI}: 1.03-1.65 ; \mathrm{P}=0.03 ; \mathrm{I}^{2}=0 \%\right)$. However, there were no differences observed in other adverse events, including bradycardia $(\mathrm{OR}=1.12 ; 95 \%$ CI: $\left.0.44-2.88 ; \mathrm{P}=0.81 ; \mathrm{I}^{2}=57 \%\right)$, pain ( $\mathrm{OR}=0.82 ; 95 \%$ CI: $\left.0.65-1.03 ; \mathrm{P}=0.09 ; \mathrm{I}^{2}=0 \%\right)$, and hypoxemia $(\mathrm{OR}=0.79 ; 95 \%$ CI: $\left.0.59-1.07 ; \mathrm{P}=0.13 ; \mathrm{I}^{2}=0 \%\right)$.

\section{Results of sensitivity and publication bias analysis}

The length of PACU stay was reported in five studies, and the pooled result showed that it was shortened by neostigmine (MD $=-17.73$; 95\% CI: -22.06 to -13.41 ; $\mathrm{P}<0.0001 ; \mathrm{I}^{2}=92 \%$; Figure 4$)$. A sensitivity analysis was performed by removing $\mathrm{Xu}$ et al.'s study (23), which reduced the $\mathrm{I}^{2}$ statistic from $92 \%$ to $86 \%$ (Figure 8), thus indicating 


\begin{tabular}{|c|c|c|c|c|c|c|c|c|c|c|c|}
\hline Study or Subgroup & \multicolumn{3}{|c|}{ Neostigmine } & \multicolumn{3}{|c|}{ Control } & \multicolumn{2}{|r|}{$\begin{array}{l}\text { Mean Difference } \\
\text { IV. Random, } 95 \% \mathrm{Cl}\end{array}$} & \multicolumn{3}{|c|}{$\begin{array}{c}\text { Mean Difference } \\
\text { IV, Random. } 95 \% \mathrm{CI}\end{array}$} \\
\hline $1.1 .1 \geqslant 40$ & & & & & & & & & & & \\
\hline Chen 2019 & 19.1 & 7.2 & 162 & 36.2 & 10.1 & 165 & $18.0 \%$ & $-17.10[-19.00,-15.20]$ & - & & \\
\hline Xu 2011 & 29.2 & 6 & 15 & 56.9 & 5.4 & 15 & $16.0 \%$ & $-27.70[-31.79,-23.61]$ & $=$ & & \\
\hline Xu 2020 & 17.8 & 4.7 & 422 & 31.2 & 9.9 & 400 & $18.5 \%$ & $-13.40[-14.47,-12.33]$ & - & & \\
\hline $\begin{array}{l}\text { Zhu } 2020 \\
\text { Subtotal }(95 \% \mathrm{Cl})\end{array}$ & 49.3 & 10.7 & $\begin{array}{r}40 \\
639\end{array}$ & 63.5 & 21.3 & $\begin{array}{r}42 \\
622\end{array}$ & $\begin{array}{l}12.3 \% \\
64.8 \%\end{array}$ & $\begin{array}{r}-14.20[-21.45,-6.95] \\
-18.11[-23.16,-13.05]\end{array}$ & $\vec{\imath}$ & & \\
\hline & \multicolumn{2}{|c|}{ Test for overall effect: $Z=7.02(P<0.00001)$} \\
\hline \multicolumn{12}{|l|}{$1.1 .2<40$} \\
\hline Xu 2011 & 32.6 & 5.3 & 15 & 56.9 & 5.4 & 15 & $16.3 \%$ & $-24.30[-28.13,-20.47]$ & $=$ & & \\
\hline Yao 2021 & 51.3 & 15.4 & 11 & 59.6 & 20.9 & 19 & $6.9 \%$ & $-8.30[-21.38,4.78]$ & & & \\
\hline $\begin{array}{l}\text { Zhu } 2020 \\
\text { Subtotal }(95 \% \text { Cl) }\end{array}$ & 51.3 & 11.5 & $\begin{array}{l}38 \\
64\end{array}$ & 63.5 & 21.3 & $\begin{array}{l}42 \\
76\end{array}$ & $\begin{array}{l}12.1 \% \\
35.2 \%\end{array}$ & $\begin{array}{l}-12.20[-19.61,-4.79] \\
-16.03[-26.51,-5.55]\end{array}$ & & & \\
\hline \multicolumn{12}{|c|}{$\begin{array}{l}\text { Heterogeneity: } \text { Tau }^{2}=67.96 ; \mathrm{Chi}^{2}=11.89, \mathrm{df}=2(P=0.003) ; \mathrm{I}^{2}=83 \% \\
\text { Test for overall effect: } Z=3.00(P=0.003)\end{array}$} \\
\hline Total $(95 \% \mathrm{Cl})$ & & & 703 & & & 698 & $100.0 \%$ & $-17.73[-22.06,-13.41]$ & $\bullet$ & & \\
\hline \multicolumn{9}{|c|}{ Heterogeneity: $\mathrm{Tau}^{2}=26.04 ; \mathrm{Chi}^{2}=74.06, \mathrm{df}=6(\mathrm{P}<0.00001) ;\left.\right|^{2}=92 \%$} & $-100-50$ & Control 50 & 100 \\
\hline
\end{tabular}

Figure 4 Forest plots of the length of stay in the post-anesthesia care unit (PACU).

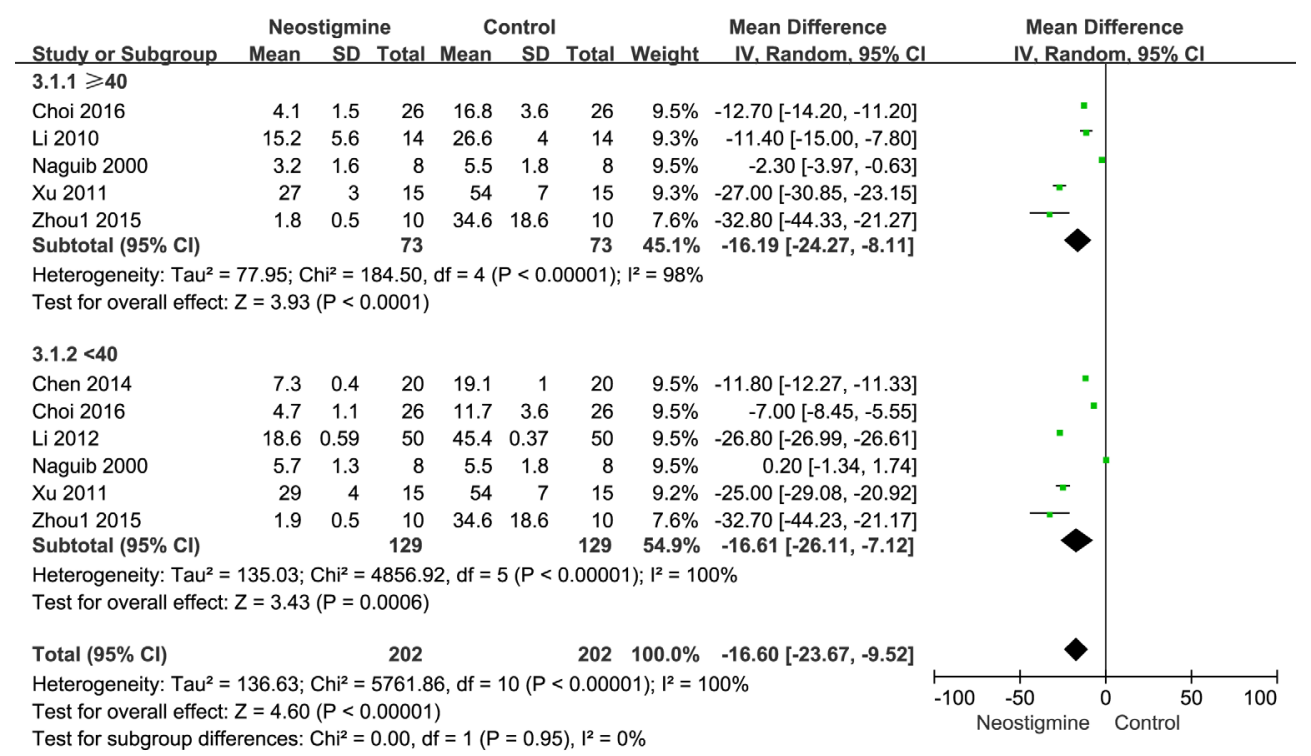

Figure 5 Forest plots for time to recovery of train-of-four ratio (TOFR) $\geq 0.9$.

that the results of the included articles were robust.

A funnel plot was created to evaluate the publication bias for the length of PACU stay. The shape was symmetrical and the $\mathrm{P}$ value of the Egger's test was 0.482 , which indicated that no significant publication bias existed in this meta-analysis (Figure 9).

\section{Discussion}

Muscle relaxants mainly act on the neuromuscular junctions, and vary in the mode, duration, and intensity of blockade. Non-depolarizing muscle relaxants competitively occupy receptors on the motor endplates in place of acetylcholine, exerting muscle relaxing effects. At the end of surgery, muscle relaxation can be reversed with neostigmine, which restores the binding of acetylcholine to receptors on the motor endplate, thereby reversing the neuromuscular block (29).

In this meta-analysis, neostigmine was found to significantly shorten both the length of stay in the PACU and the extubation time $(\mathrm{P}<0.05)$. These results, which are consistent with the results of Lu's research (30), suggest that 


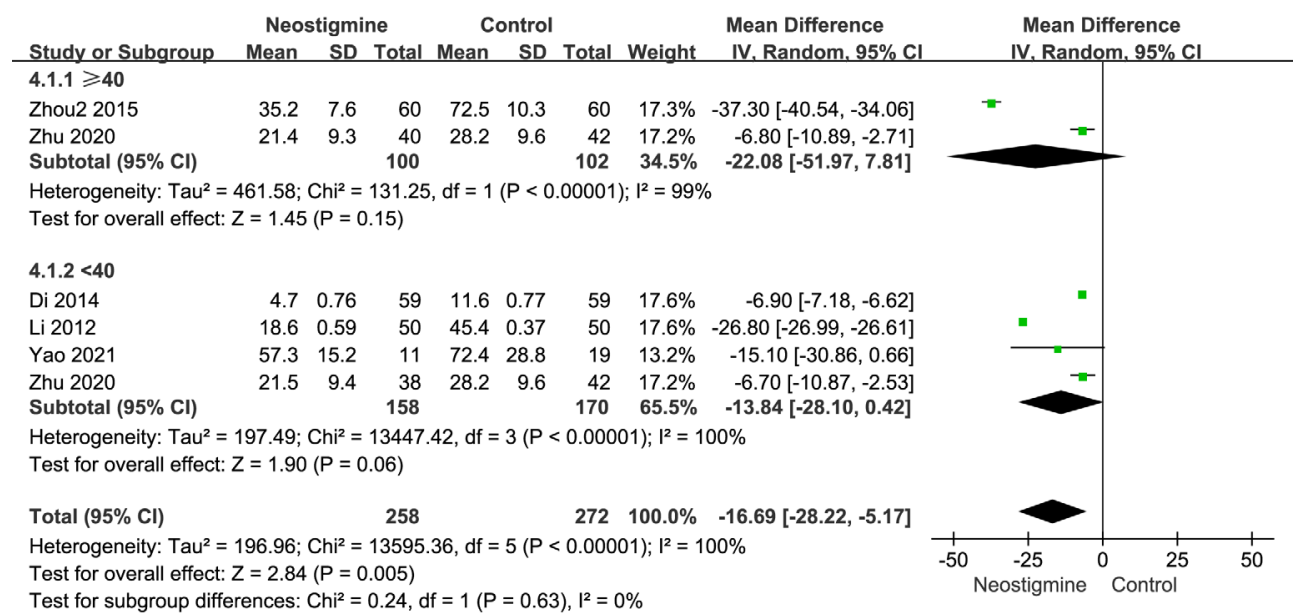

Figure 6 Forest plot of the extubation time.

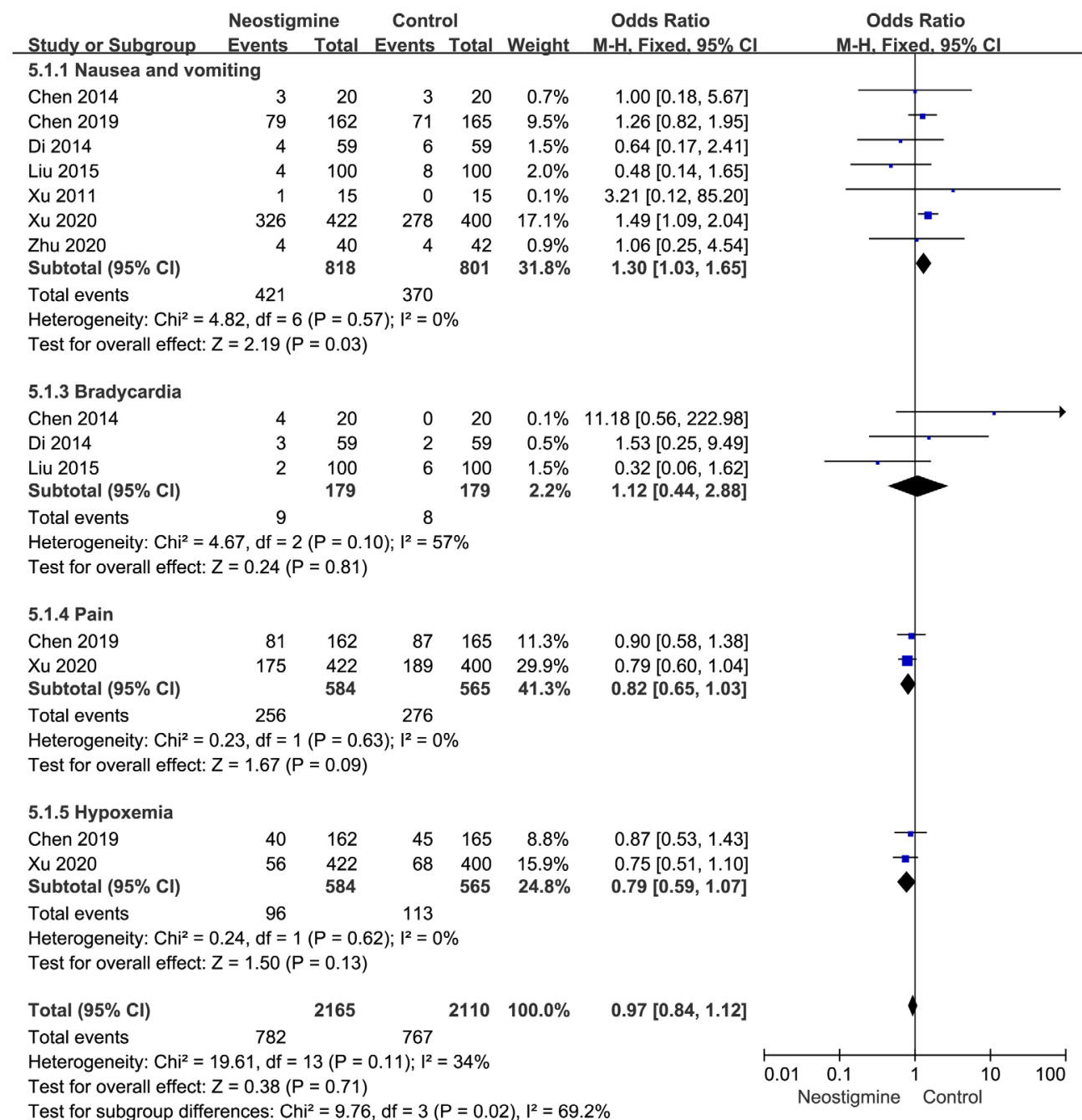

Figure 7 Forest plot of adverse events. 


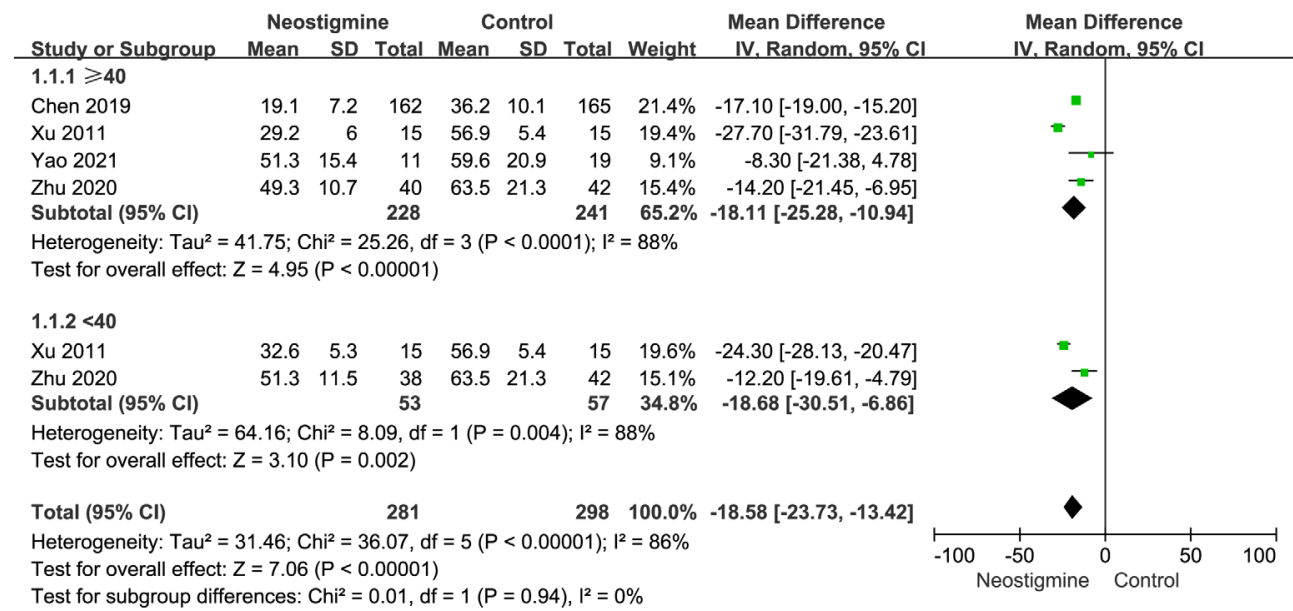

Figure 8 Sensitivity analysis forest plots of the length of stay in the post-anesthesia care unit (PACU).

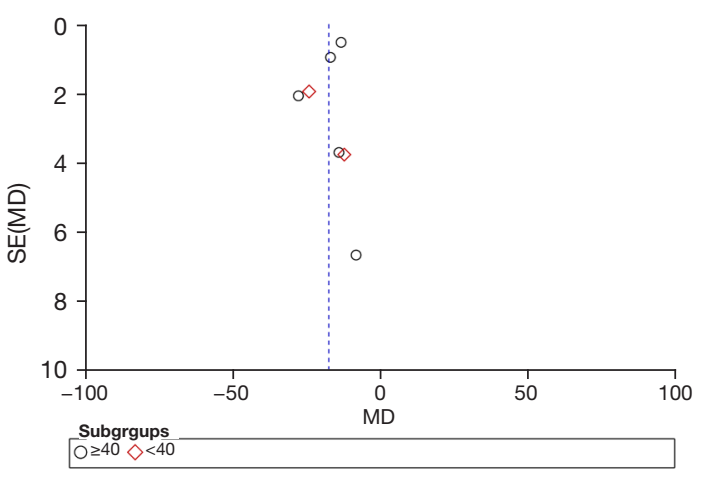

Figure 9 Publication bias funnel plot for the length of stay in the post-anesthesia care unit (PACU).

neostigmine can accelerate the rehabilitation of patients. Further, regardless of whether the dose was high or low, patients who received neostigmine had a short PACU stay.

TOF is a medical test used to assess the degree of paralysis. The TOF value can precisely reflect the degree of muscle relaxation, and has been widely applied clinically to assess the degree of intraoperative and postoperative residual muscle relaxation. When non-depolarizing muscle relaxants are used, neuromuscular monitoring is essential throughout the whole anesthesia process. Recovery of the TOFR to 0.7 has been reported to provide insufficient confirmation of the complete recovery of the swallowing muscles and upper respiratory tract; instead, a TOFR of 0.9 should be taken as confirmation of complete recovery before extubation (31). This meta-analysis showed that neostigmine can enhance the recovery of the TOFR, which is also in consistent with Lu's research findings (30). In the low-, medium-, and high-dose subgroups, neostigmine significantly shortened the time to recovery of TOFR $\geq 0.9$. When the dose of neostigmine was increased from 20 to $40 \mu \mathrm{g} / \mathrm{kg}$, the recovery of muscle relaxation was significantly accelerated, but with an increase to $60 \mu \mathrm{g} / \mathrm{kg}$, only the time to recovery of TOFR $\geq 0.7$ was shortened, with limited clinical significance (32).

In this meta-analysis, we found that neostigmine did not cause an increase in postoperative total adverse events such as bradycardia, hypoxemia, and postoperative pain. Neostigmine can mitigate hypoxemia; however, no significant difference between the neostigmine and control groups was observed in this analysis, which may be attributable to the limited number of studies included that reported this outcome. The relationship between neostigmine and the incidence of PONV remains controversial $(33,34)$. Although this meta-analysis showed that neostigmine elevated the risk of PONV, further study is needed to confirm this observation. Also, the use of muscle relaxants during anesthesia has been reported to be associated with an increased risk of postoperative pulmonary complications (2). Together, these observations serve as a reminder that neuromuscular monitoring and reversal agents may reduce the risk of postoperative pulmonary complications.

This study has some potential limitations that should be mentioned. First, significant heterogeneity existed between the studies, and the small sample sizes of each study did not allow for meta-regression or additional sensitivity analyses; instead, a random-effects model was applied for 
meta-analysis. Second, included quantitative researches on neostigmine is insufficient. Further, the included studies were mostly performed in Asia, and there was a lack of relevant studies from other geographical areas. Neither of these factors is conducive to the wider generalization of our conclusions. In addition, the comparison between Neostigmine and Sugammadex is not conducted, which could be analyzed in the future. To conduct more in-depth scientific research on this topic, more studies from nonAsian countries and more quantitative analyses should be conducted in future.

In conclusion, this comprehensive meta-analysis of 14 studies has demonstrated that neostigmine is safe and effective for neuromuscular blockade reversal in patients recovering from general anesthesia. Neostigmine shortened the length of stay in the PACU, the extubation time, and the time to recovery of TOFR $\geq 0.9$, with limited overall incidence of adverse events.

\section{Acknowledgments}

Funding: None.

\section{Footnote}

Reporting Checklist: The authors have completed the PRISMA reporting checklist. Available at https://dx.doi. org/10.21037/atm-21-5667

Conflicts of Interest: All authors have completed the ICMJE uniform disclosure form (available at https://dx.doi. org/10.21037/atm-21-5667). The authors have no conflicts of interest to declare.

Ethical Statement: The authors are accountable for all aspects of the work in ensuring that questions related to the accuracy or integrity of any part of the work are appropriately investigated and resolved.

Open Access Statement: This is an Open Access article distributed in accordance with the Creative Commons Attribution-NonCommercial-NoDerivs 4.0 International License (CC BY-NC-ND 4.0), which permits the noncommercial replication and distribution of the article with the strict proviso that no changes or edits are made and the original work is properly cited (including links to both the formal publication through the relevant DOI and the license). See: https://creativecommons.org/licenses/by-nc-nd/4.0/.

\section{References}

1. Kehlet H, Dahl JB. Anaesthesia, surgery, and challenges in postoperative recovery. Lancet 2003;362:1921-8.

2. Kirmeier E, Eriksson LI, Lewald H, et al. Post-anaesthesia pulmonary complications after use of muscle relaxants (POPULAR): a multicentre, prospective observational study. Lancet Respir Med 2019;7:129-40.

3. Hayes AH, Mirakhur RK, Breslin DS, et al. Postoperative residual block after intermediate-acting neuromuscular blocking drugs. Anaesthesia 2001;56:312-8.

4. Ali HH, Utting JE, Gray C. Stimulus frequency in the detection of neuromuscular block in humans. Br J Anaesth 1970;42:967-78.

5. Murphy GS, Brull SJ. Residual neuromuscular block: lessons unlearned. Part I: definitions, incidence, and adverse physiologic effects of residual neuromuscular block. Anesth Analg 2010;111:120-8.

6. Viby-Mogensen J, Jørgensen BC, Ording H. Residual curarization in the recovery room. Anesthesiology 1979;50:539-41.

7. Murphy GS, Szokol JW, Franklin M, et al. Postanesthesia care unit recovery times and neuromuscular blocking drugs: a prospective study of orthopedic surgical patients randomized to receive pancuronium or rocuronium. Anesth Analg 2004;98:193-200.

8. Eikermann M, Groeben H, Hüsing J, et al. Accelerometry of adductor pollicis muscle predicts recovery of respiratory function from neuromuscular blockade. Anesthesiology 2003;98:1333-7.

9. Eriksson LI, Sundman E, Olsson R, et al. Functional assessment of the pharynx at rest and during swallowing in partially paralyzed humans: simultaneous videomanometry and mechanomyography of awake human volunteers. Anesthesiology 1997;87:1035-43.

10. Bissinger U, Schimek F, Lenz G. Postoperative residual paralysis and respiratory status: a comparative study of pancuronium and vecuronium. Physiol Res 2000;49:455-62.

11. Sundman E, Witt H, Olsson R, et al. The incidence and mechanisms of pharyngeal and upper esophageal dysfunction in partially paralyzed humans: pharyngeal videoradiography and simultaneous manometry after atracurium. Anesthesiology 2000;92:977-84.

12. Yu B, Ouyang B, Ge S, et al. Incidence of postoperative residual neuromuscular blockade after general anesthesia: a prospective, multicenter, anesthetist-blind, observational study. Curr Med Res Opin 2016;32:1-9.

13. Nair VP, Hunter JM. Anticholinesterases and 
anticholinergic drugs. Continuing Education in Anaesthesia Critical Care \& Pain 2004;5:164-8.

14. Kopman AF, Yee PS, Neuman GG. Relationship of the train-of-four fade ratio to clinical signs and symptoms of residual paralysis in awake volunteers. Anesthesiology 1997;86:765-71.

15. Chen Z, Shi J, Bao Y, et al. Dose-effect relationship study of Neostigmine antagonizing Cisatracurium residual paralysis in elderly patients after surgery. China Medical Herald 2014;11:87-91.

16. Chen YJ, Xu K, Lu ZJ. Effect of neostigmine antagonizing cisatracurium on postoperative recovery in elderly patients. Journal of Chinese Physician 2019;21:730-3.

17. Choi ES, Oh AY, Seo KS, et al. Optimum dose of neostigmine to reverse shallow neuromuscular blockade with rocuronium and cisatracurium. Anaesthesia 2016;71:443-9.

18. Di HP, He BT, Yu XQ. Effect of neostigmine on residual muscle relaxation after CIS atracurium general anesthesia. Modern Journal of Integrated Traditional Chinese and Western Medicine 2014;23:3958-60.

19. Li JX, Ding LX. Effect of neostigmine on muscle relaxation of vecuronium in tonsillectomy in children. Medical Innovation of China 2012;9:19-20.

20. Li YF, Ouyang BY, Ran J. Timing analysis of neostigmine antagonizing cisatracurium muscle relaxant effect. Guangdong Medical Journal 2010;31:2022-4.

21. Liu Y, Xu MJ, Zhao GS. Clinical observation of low dose neostigmine antagonizing residual muscle relaxation after gynecological laparoscopic general anesthesia. Chinese Journal of Clinicians 2015;43:81-3.

22. Naguib M, Riad W. Dose-response relationships for edrophonium and neostigmine antagonism of atracurium and cisatracurium-induced neuromuscular block. Can J Anaesth 2000;47:1074-81.

23. Xu K, Chen YJ, Lu ZJ, et al. Effects of neostigmine Muscle relaxation Antagonism on Postoperative Recovery of Patients Undergoing Laparoscopy under General Anesthesia. Medical Recapitulate 2020;26:3067-71.

24. Xu FL, Zhang W, Fang C. Reasonable reversal of neuromuscular block in the postanesthesia care unit. Anhui
Medical and Pharmaceutical Journal 2011;15:1374-6.

25. Yao M, Shi H, Jiao B, et al. Effect of neostigmine antagonistic timing on residual muscle relaxation after general anesthesia -- a randomized, double-blind, parallel controlled study. Chinese Journal of Hospital Pharmacy 2021;41:191-4.

26. Zhou JQ, Chen XM, Xu H. Comparison of mild residual muscle relaxation effects of neostigmine at different doses against rocuronium and vecuronium in children. The Journal of Practical Medicine 2015;31:4123-4126.

27. Zhou JS, Zeng LZ, Anesthesiology D, et al. Antagonistic management of prolonged muscle relaxant time after rocuronium bromide in senile anesthesia. China Practical Medicine 2015;10:29-30.

28. Zhu B, Sun D, Yang L, et al. The effects of neostigmine on postoperative cognitive function and inflammatory factors in elderly patients - a randomized trial. BMC Geriatr 2020;20:387.

29. Nell WT, Stevenson N, Ridgard T, et al. Post-operative neuromuscular function of patients receiving nondepolarising muscle relaxants at Universitas Hospital, Bloemfontein, South Africa. Southern African Journal of Anaesthesia \& Analgesia 2004;10:6-8.

30. Lu CL, Wei HQ. Clinical observation of muscle relaxation monitoring during recovery from general anesthesia. Information of Medical Equipment 2017;38:1222-5.

31. Hunter JM. Reversal of residual neuromuscular block: complications associated with perioperative management of muscle relaxation. Br J Anaesth 2017;119:i53-62.

32. Lu ZJ, Wang Y, Yu BW. Effect of neostigmine on the recovery of vecuronium muscle relaxation. Chinese Journal of Anesthesiology 2004:63-64.

33. Tramèr MR, Fuchs-Buder T. Omitting antagonism of neuromuscular block: effect on postoperative nausea and vomiting and risk of residual paralysis. A systematic review. Br J Anaesth 1999;82:379-86.

34. Cheng CR, Sessler DI, Apfel CC. Does neostigmine administration produce a clinically important increase in postoperative nausea and vomiting? Anesth Analg 2005;101:1349-55.
Cite this article as: Ji W, Zhang X, Liu J, Sun G, Wang X, Bo L, Deng X. Efficacy and safety of neostigmine for neuromuscular blockade reversal in patients under general anesthesia: a systematic review and meta-analysis. Ann Transl Med 2021;9(22):1691. doi: 10.21037/atm-21-5667 